Department of Economics and Finance

\author{
University of Guelph
}

Discussion Paper 2018-03

\title{
Closed-loop Supply Chain Games with Innovation-led Lean Programs and Sustainability
}

$$
\text { By: }
$$

Talat S. Genc

University of Guelph tgenc@uoguelph.ca
Pietro De Giovanni

ESSEC Business School pietro.degiovanni@essec.edu 


\title{
Closed-loop Supply Chain Games with Innovation-led Lean Programs and Sustainability
}

\author{
Talat S. Genc* \\ College of Business and Economics, University of Guelph, Guelph, Ontario, Canada \\ Pietro De Giovanni \\ Department of Operations Management, ESSEC Business School, Paris, France
}

June 1, 2018

\begin{abstract}
This paper studies the impact of some innovation-led lean programs in a Closed-loop Supply Chain (CLSC) setting. We use a game-theoretic approach to model a CLSC composed of one supplier and one manufacturer. The supplier sets the wholesale price of an intermediate product while the manufacturer sets the selling price of a final product. Further, the manufacturer invests in innovation-led lean practices to entail both a strategic effect and a process innovation effect. The strategic effect consists of responsiveness involving the CLSC's capacity to properly respond to consumers' needs and leading to increase in sales. Further, the strategic effect enhances sustainability as consumers align their behavior to the CLSC's attitude of reducing the waste through lean, thus using their products for longer time period and entirely exhausting their residual value. Innovation-led lean practices also generate a process innovation effect, which consists of the marginal production cost abatement. Our findings indicate that lean practices leading to both strategic and process innovation are profitable for the manufacturer and sponsor sustainability. When only one of those can be presented, CLSCs should prefer the adoption of a strategic lean program. From its side, the supplier is much less sensitive to environmental benefits, thus it focuses on sales and operational matters. Furthermore, in a centralized CLSC, the preferences for strategic vs. process innovation lean follow the same path of the decentralized CLSC. Nevertheless, we pinpoint that the manufacturer in the decentralized CLSC has a larger incentive to adopt a strategic lean program than in the centralized CLSC. Also, the supplier always obtains larger economic benefits in the decentralized CLSC under any type of innovation-led lean program.
\end{abstract}

\footnotetext{
${ }^{*}$ Corresponding author. Email: tgenc@uoguelph.ca Phone: 1-519-824-4120 ext 56106. We thank the guest editor and anonymous referees for constructive remarks and helpful suggestions.
} 
Keywords: Closed-loop Supply Chain; Innovation-led Lean; Process Innovation; Sustainability;

Used-product returns; Vertical Integration

\section{Introduction}

While the recent research has shown the interlinks between Lean practices and Supply Chain Management (see Martinez-Jurado and Moyano-Fuentes, 2014 for a recent review), the literature has overlooked the Lean applications within Closed-loop supply chain (CLSC) settings. The latter can be defined by integration between traditional flows of raw materials, goods, and information, with the reverse flows of past sold products (Guide and Van Wassenhove 2002). The implementation of innovation-led lean programs within CLSCs becomes more challenging than their adoption in traditional supply chains, as issues of sustainability, process innovation and performance need a deeper evaluation.

We contribute by investigating a CLSC model in which firms invest in innovation-led lean programs to reduce the waste within the chain accounting for several types of strategic and tactical implications. The network of relationships that we explore is displayed in Figure A. To our knowledge, this is the first research on CLSC that incorporates innovation-led lean programs within firm strategies. Differently from traditional lean practices, innovation-led lean programs achieve all traditional lean targets by a concrete focus on innovation. These programs will have a dual effect in CLSC.

$<<$ Insert FIGURE A here $>>$

On the one hand, they generate a "strategic effect" through their direct influence on the consumers' preferences and choices. The strategic effect is then divided into responsiveness and sustainability. Responsiveness links system capacity of making superior deliveries to consumers, in terms of higher quality products, better price, shorter delivery time, and highly customizable products (Shan et al., 2013). The implementation of innovation-led lean programs allow firms to better perform the deliveries, reducing all lead times. Consumers feel, perceive and experience all these improvements that a CLSC obtains through the lean practices, thus exerting a certain willingness to purchase (Lluis, 2002). Therefore, our first contribution to the literature of CLSC is to consider the responsiveness effects induced by innovation-led lean programs as a better way for achieving costumer satisfaction and higher sales.

Furthermore, the strategic effect also exerts a sustainability effect causing consumers to be more environmentally responsible. Through innovation-led lean programs consumers recognize 
that firms heavily commit on the environmental conservation and preservation (Pil and Rothenberg, 2003), increasing the consumer attention on the firms' green policy (Reser and Bentrupperbaumer, 2005). Thus, innovation-led lean programs translate into a more responsible behavior adopted by consumers who also wish to be more sustainable by using their products for a long time period (increasing the residence time: De Giovanni, 2016) and reduce the waste returned within the CLSC or dispersed in the landfill. Thus, our second contribution to the CLSC literature is to account for the sustainability effect entailed by innovation-led lean programs, which is exemplified by consumers being more environmentally responsible (Reser and Bentrupperbaumer, 2005).

On the other hand, innovation-led lean programs exert an operational impact on the production processes by identifying mistakes earlier, correcting them, improving the work environment and conditions, cutting the inventory in all stages of the production process, engaging in flexible production process and requiring less working space. Any time firm invests in innovation-led lean programs the marginal production cost (and thus the process innovation impact) is modified with either a positive or a negative sign. The literature has mainly focused on the positive contribution that lean exerts in terms of process innovation, basically linked to introducing some practices to become more efficient (Martinez-Jurado and Moyano-Fuentes, 2014 ) as well as using returns to make new goods to save in terms of virgin materials, water consumption, energy consumption and emissions (Savaskan et al., 2004). Nevertheless, within the context of CLSCs and sustainability, firms can also observe a negative sign when making sustainable products and treating returns are more expensive than making traditional products. For example, producing electric car is more expensive than producing fossil fuel-burning vehicles (Atasu et al., 2012). Consequently, investing in innovation-led lean programs within CLSC can bring either a positive or a negative process innovation effect. Our third contribution to the literature is to distinguish and investigate both positive and negative sides of innovation-led lean programs and evaluate how firms should pursue lean objectives considering sustainability, process innovation and performance simultaneously.

In sum, we contribute to the CLSC literature by developing game-theoretic models based on innovation-led lean programs to bridge the areas of lean as process innovation (efficiency), lean as responsiveness and sustainability, and the CLSC issues. In our model, we implement a Stackelberg competition game (von Stackelberg, 2011) in which a supplier produces a component and sells it at a wholesale price to a manufacturer; the manufacturer takes this component to make the final product, which will be sold to consumers at a certain price. The consumers return the used-product directly to the manufacturer to close the loop. The manufacturer invests in innovation-led lean programs to exploit the responsiveness through increased sales, sustainability through an ad-hoc return policy, and process innovation effect by evaluating the impact of innovation- 
led lean programs on operations. In a decentralized CLSC the supplier is the Stackelberg leader and decides the wholesale price after considering the manufacturer's strategies. We show that the both firms enjoy the implementation of innovation-led lean programs that aim at responsiveness, sustainability and process innovation. Nevertheless, increasing sensitivity of consumers for environmental concerns does not always bring out a Pareto-improving situation. Within this space, the supplier would push more for sustainability while the manufacturer would push more for process innovation. Interestingly, the manufacturer's profits get improved quicker than the supplier's profits under strategic lean programs, thus exploiting responsiveness and process innovation effects. This highlights the finding that lean practices embedded into CLSC framework can yield non-trivial complications and insights. Nevertheless, when innovation-led lean programs negatively impact the production process, CLSCs should implement lean practices only if responsiveness is present. In such a case, sustainability alone is not sufficient to guarantee a superior performance to manufacturers.

Finally, we solve for the centralized CSLC to remove the double marginalization effect from our analysis. Interestingly, our findings show that the centralized CSLC sets the strategies with the same criteria of a decentralized CLSC. Nevertheless, the preferences for investments in innovation-led lean programs that aim at strategic lean vs. process innovation lean are only partially aligned to the decentralized case. In fact, the centralized CLSC prefers a shift from process innovation to strategic lean smoother than the manufacturer and quicker than the supplier. Thus, the absence of a double marginalization does not translate into enjoying the benefits of lean earlier. As in the decentralized setting, a negative effect of innovation-led lean programs on process innovation should be corroborated by a heavy presence of responsiveness effect as sustainability alone cannot overcome the negative influence of lean practices on process innovation.

The paper is organized as follows. Section 2 covers the relevant literature. Section 3 introduces the CLSC model and assumptions. Section 4 presents the equilibria in the decentralized CLSC while Section 5 investigates the strategic and the process innovation lean programs separately. Section 6 deals with the centralized CLSC solution. Section 7 examines a special case involving a negative process innovation lean. Section 8 covers a discussion of findings and provides managerial insights for firms operating in real-life industries. Section 9 concludes with limitations and future research avenues.

\section{Literature Review}

The literature of Operations and Supply Chain Management has largely emphasized the role of Lean Manufacturing on firms and supply chains performance. In particular, Lean Manufacturing is defined as an integrated manufacturing system that seeks to optimize the production resources utilization without involving an extra cost while minimizing the waste such as inventories (Chavez et al., 2015). Lean Manufacturing involves uti- 
lization of various techniques (Yang et al., 2011) and covers almost everything starting from product concept to its distribution (Jasti and Kodali, 2014). The valuable discussion around the triple bottom line topic has increased the attention of researchers in Lean Manufacturing as lean programs should aim at higher levels of performance (Gimenez et al., 2012) rather than focusing only on operational targets. The recent research has been developed around the adoption of several lean programs to achieve the environmental targets thanks to the adoption of new green manufacturing practices, raw material reduction and environmental design (e.g., Gotschol et al., 2014). Accordingly, firms can abate the negative effect of their operations on the environment. In this perspective, the lean practices have been shown to be effective only in some specific cases in the short run (e.g., Sawhney et al., 2007) while some doubts remain regarding their benefits in the medium-long run (Lucey et al., 2005).

The literature of Operations and Supply Chain Management has extensively investigated the role of lean practices that put more emphasis on innovation, namely, innovation-led lean programs. The latter are able to achieve achieve objectives of responsiveness and process innovation improvements. First, innovation-led lean programs target higher responsiveness, which is defined as the system capability to promptly and properly respond to a need (Handfield and Bechtel, 2002). According to Shan et al.(2013), lean practices reduce the waste over a production system, translating to a larger system responsiveness. Lluis (2002) suggests a method to increase the responsiveness through lean practices by reducing waste, increasing productivity and compressing the service time. De Giovanni et al. (2014) suggest to enhance responsiveness within the supply chain by undertaking supplier integration, modularity and integrated IS. Jari and Harri (2004) identify the opportunities to increase responsiveness through standardized practices, modularized products, and shorter lead times. Higher responsiveness leads to reduced delivery time, better service, higher quality through fast controls, consumer's willing to purchase from faster systems, better information flow, less obsolete inventory and flexible production (e.g., Handfield and Benchtel, 2002; De Giovanni et al., 2014; Shan et al., 2013). Therefore, the firms aim at implementing lean practices to achieve better responsiveness and increase profitability. Second, innovation-led lean programs entail process innovation benefits by achieving just in time delivery, minimizing the work in process and allowing for a better usage of available materials, independent of whether it is virgin material or used material. Workers can be trained for changing some of the production routines to be better organized in teams, be responsible in their output and given incentive for continuous improvement (Rothenberg et al., 2001). More in general, the implementation of some process innovation practices to reduce the production cost has been investigated in several works by Kobayashi (2015) and D'Aspremont and Jacquemin (1988).

The current discussions of benefits of lean practices on responsiveness and process innovation need to be extended to account for sustainability targets. In particular, the supply chain studies sponsor the investigation 
of CLSCs as valid frameworks to consider sustainability targets (e.g., Guide and van Wassenhove, 2009) along with more operational targets like responsiveness and process innovation (Ostlin et al., 2008). Sustainability in CLSC refers to the environmental performance that such supply chain types achieve when managing the waste (Guide et al., 2009; Souza, 2013). One of the most important KPI associated to CLSCs is the return rate, representing the number of returns that end up with at the manufacturer's plants (De Giovanni et al., 2016). This is very much in the vein of lean practices involving reduction of waste, pollution and energy consumption obtained by production from using the returns rather than using virgin materials (Savaskan et al., 2004; Savaskan and van Wassenhove, 2006).

$<<$ Insert TABLE 1 here $>>$

We identify and summarize in Table 1 lean programs and innovation-led lean programs that have implications in CLSCs regarding responsiveness, process innovation and sustainability. Within this framework, we have mainly identified a major research gap that the literature leaves out is composed of two main pillars. First, when CLSCs adopt innovation-led lean practices to collect and treat past-sold products to make new goods, the production process does not become necessarily more efficient as the literature stated (Davenport, 1993; Kobayashi, 2015). The major problems come from the difficulties in extracting the residual value from returns. For example, H\&M initiated a collection campaign of clothes to reuse the collected cotton in the production of new clothes. The extraction of cotton from used clothes is time consuming and expensive, thus the adoption of innovation-led lean programs to reduce inventory and lead time and increase quality is not resolved. The second major pillar that CLSCs leave out is the trade-off between responsiveness and returns. Investing in lean practice leads to better quality and superior goods (e.g., Lluis, 2003; Pil and Rothenberg, 2003), faster and more efficient deliveries (e.g., Bortolotti et al., 2014; Rothenberg et al., 2001) and price reduction through savings (e.g., Gonzales-Benito, 2005). Therefore, they truly entail for high responsiveness and considerable process innovation benefits. Nevertheless, because consumers are exposed to purchase superior products, they utilize those for longer time periods, reduce the number of returns and postpone the repurchases (e.g., Souza, 2013; De Giovanni and Zaccour, 2018). From a sustainability point of view, this is a good achievement as CLSCs extend the residence time generating less waste in the landfill (e.g., Souza, 2013). At the same time, CLSCs experience a reduction of returns, implying a heavier use of virgin materials for making new products. The literature mainly focuses on increasing the number of returns as much as possible to save on operations (Savaskan et al., 2004). Instead, investing in lean practices makes this target more challenging due to the aforementioned trade-off between responsiveness targets and sustainability objectives. The literature on innovation-led lean programs leaves a gap that consists of these two 
points. For example, as reported in Table 1, the implementation of some innovation-led lean programs like six-sigma and Total Quality Management allows firms to achieve responsiveness, sustainability and process innovation efficiency (e.g., Dora et al., 2013; Bortolotti et al., 2014; Yang et al., 2011). Nevertheless, those programs do not consider the operational and market challenges that firms face. For example, collecting old gasoline-burning cars while producing electrical cars is extremely inefficient: Old cars can only be recycled rather than reused while making electrical cars requires new and more expensive technologies and processes. Further, electrical cars designed through innovation-led lean practices last longer time periods, thus consumers postpone the product replacement implying delayed sales for manufacturers.

In this paper, we aim at fulfilling this gap by comprehensively analyzing the role of innovationled lean programs in CLSC that accounts for responsiveness, sustainability and process innovation efficiency and consider the emerging (aforementioned) trade-offs. We develop a game-theoretic model in which a manufacturer invests in some innovation-led lean programs and evaluates their implications to set the best strategies. We start from the analysis of a simple return function as in Ostlin et al. (2008), where returns are exogenous (passive return rate) and make a further contribution by modeling the returns as a function of the innovation-led lean investment. This follows a recent trend in the CLSC literature in which the returns can be a function of a firm's strategy, e.g., Genc and De Giovanni (2017), Hong et al. (2017), Esenduram et al. (2016) and Kaya (2010). At the same time, the literature of CLSC has shown that firms can get a market option when the market recognizes their contributions to the environment and the society (e.g., Ramani and De Giovanni, 2017). This is in line with recent papers in Green Marketing according to which pro-environmental values implemented by firms lead to pro-environmental consumer behavior (Reser and Bentrupperbaumer, 2005). More in general, environmental values that CLSCs communicate as a result of lean practices (e.g., waste reduction) play a primary role in consumer pro-environmental behavior: values affect people's beliefs, which then have influences on personal norms that lead to consumers' pro-environmental behaviors (Reser and Bentrupperbaumer, 2005).

\section{Model}

We consider several related closed-loop supply chain (CLSC) structures to examine the impact of innovationled lean programs on the chain performance and sustainability. In these supply chains, firms engage in vertical relations. An upstream supplier $(S)$ makes an intermediate good (e.g., car engine) while a downstream manufacturer $(M)$ buys this intermediate good and produces the final product (e.g., automobile). $M$ sells it to consumers $(C)$. Consumers can choose to return their used products to $M$ depending on CLSC's 
Table 2: Model Notation

\begin{tabular}{|l|l|}
\hline Notation & Description \\
\hline$M(S)$ & Firm $M(S)$ \\
\hline$v$ & Quantity of used product return \\
\hline$\theta$ & The maximum number of return without lean \\
\hline$r$ & Rebate per return \\
\hline$L_{M}$ & Lean activity level \\
\hline$\sigma$ & Rate of environmental benefit \\
\hline$p$ & Price of the final product \\
\hline$q$ & Quantity of final product \\
\hline$\alpha$ & Market potential without lean \\
\hline$\beta$ & Price response rate \\
\hline$\eta$ & Consumer response rate to lean process \\
\hline$c_{M}$ & Marginal production cost for $M$ \\
\hline$b_{M}$ & Marginal benefit of lean to cost of production for $M$ \\
\hline$\Delta_{M}$ & Marginal net benefit of collection \\
\hline$c_{S}$ & Marginal production cost for $S$ \\
\hline$b_{S}$ & Marginal benefit of lean to cost of production for $S$ \\
\hline$w$ & Wholesale price of the intermediate product \\
\hline
\end{tabular}

environmental attitudes. The returned products provide an exogenous benefit to $M$ which is $\Delta_{M}$. We assume that the returned items cannot be used in $M$ 's production processes directly but can be sold in another market.

In this CLSC, innovation-led lean programs generate a process innovation effect, a responsiveness effect and a sustainable outcome. While process innovation is an operational activity that affects the marginal production cost (process innovation effect), innovation-led lean programs also target consumers' returns and demand (strategic effect). Lean programs allow $M$ to make products of superior quality, thus the consumers attempt to return it late and therefore generate less waste in the future. While these innovationled lean programs are carried out by the manufacturer, they impact decisions of all parties $(S, M, C)$ and the performance of the entire supply chain. The end-users/consumers $(C)$ are environmentally conscious (caring about lean activities including environment-friendly product developments and improvements), and respond to product price. They positively contribute to the environment by returning their used products to the collector $M$.

We are interested in solving for supply chain equilibrium decisions of $(S, M, C)$ using a Stackelberg framework respecting the channel power of the upstream supplier $S . M$ chooses retail price $p$ and the level of lean $L$ to maximize its profit, while $S$ sets the wholesale price $w$. In Table 2 we display the model notation.

Demand for the final product is

$$
q(p, L)=\alpha-\beta p+\sigma L
$$

where $p$ is the final product price per unit and $L$ is the lean investment. All demand coefficients $\alpha, \beta$ 
and $\sigma$ are strictly positive and correspond to the market potential, the consumers' sensitivity to price and the consumers' sensitivity to lean efforts, respectively. While the parameters $\alpha$ and $\beta$ are highly justified in the economics literature (see Tirole and Funderberg, 1996), the interpretation of $\sigma$ is as follows: When firms invest in innovation-led lean programs, firms are able to better respond to the consumers' needs, thus producing superior goods and services to the market. $\sigma$ measures the sales increase due to such recognition and highlights the idea that being lean is a marketing opportunity to develop the business (Shan et al., 2013; Lluis, 2002). When $\sigma=0$, consumers are not able to link the innovation-led lean programs to any benefits. Otherwise, $\sigma>0$ represents a value option that firms can exploit to increase their consumer base (Ramani and De Giovanni, 2017).

Some consumers can also return their used products, and the number of returns is determined by

$$
v(L)=\theta-\eta L
$$

where consumers respond to the lean practice positively and would like to hold onto their products as long as possible $(\eta \geq 0)$. That is, the higher the lean innovation investments, the lower is the returns. This assumption is in line with Pil and Rothenberg (2003), according to which lean practices imply changes in equipment, tools, software, skills to produce more socially- and environmentally-friendly goods. Thus, the entire production process provides less resource waste, emissions and pollution (Zhu and Sarkis, 2004). When $\eta=0$, consumers do not recognize the firms' capacity to produce goods without deteriorating social and environmental responsibility. Thus, they also adopt non-environment friendly behavior by returning the maximum number of goods, $\theta$. Instead, when $\eta>0$, consumers align their returning behavior to the firms' attitudes of being socially- and environmentally-friendly through their lean investments. This alignment implies a lower number of returns, thus people use their products for longer time periods generating less amounts in the landfill.

Note that the terms $\sigma L$ inside Eq. (1) and $\eta L$ inside Eq. (2) correspond to the benefits that innovation-led lean programs supply to both the demand and the returns. Nevertheless, these two components also generate an interesting trade-off: Firms increase their sales when investing in innovation-led lean programs; at the same time, the consumers align their returning behavior to the firms' targets, that is, reducing the negative impact of the business on the environment. Thus, they return old goods less frequently to exploit all the residual value. This implies a lower amount of rewards for firms, as they cannot use returns to produce new products (Savaskan et al., 2004).

The $M$ 's total cost is linear in output $q$ and the marginal production $\operatorname{cost} c_{M} \geq 0$ is constant per output. $M$ can also implement some lean programs aiming at reducing the marginal production cost, thus leading to 
process innovation investments. In particular, the marginal production cost can be decreased by $b_{M}>0$. This is the aim of a process innovation: reducing the impact of operations by reducing the marginal production cost (Davenport, 1993). Therefore, the total production cost function takes the form:

$$
C_{M}(q, L)=\left(c_{M}-b_{M} L\right) q
$$

Note that the term $b_{M} L$ explains the operational benefits that a lean program supplies. Although $b_{M}>0$ is an assumption that follows the extensive literature on process innovation (Kobayashi, 2015), several recent contributions reveal that when process innovation is linked to green objectives it does not necessarily lead to lower production costs. For example, Bhoovaraghavan et al. (1996) compared the case of producing conventional cars vs. electric cars and found that process innovation strategies generate operational benefits for the production of conventional vehicles but not necessarily for electric cars. More recently, CarrilloHermosilla et al. (2010) show that an "end of pipe" green process innovation has a detrimental effect on the production cost as compared to a conventional innovation process (as an example of car painting, see Geffen \& Rothenberg, 2000). Accordingly, we develop a further analysis when considering the operational benefits, $b_{\mathbf{M}}<0$. In such a case, $M$ can still hold the strategic effects but fully loses the process innovation effects. The implementation of some lean programs implies some investment costs, which take the quadratic form:

$$
C_{L}(L)=L^{2} / 2
$$

This is a classical assumption in the game theory literature when firms invest in process innovation (e.g., Genc, 2017) as the quadratic and convex form reflect some real firms' investments. The innovation-led lean programs $L$ create synergies in the vertical chain and bear fruits to all parties. They impact final product demand (through sustainability program), and the cost of production (through process innovation). Furthermore, innovation-led lean programs affects sustainability through return.

The $M$ maximizes its profit function by optimally choosing its price and the lean investments:

$$
\max _{p, L} \Pi^{M}=\underbrace{q(p, L)\left(p-w-c_{M}+b_{M} L\right)-C_{L}(L)}_{\text {Forward profit }}+\underbrace{v(L) \Delta_{M}}_{\text {Backward profit }}
$$

$S$ chooses wholesale price $w$ for the intermediate product. We assume that there is one-to-one relation between the intermediate product and the final product. That is, one unit of intermediate product will be used to make one unit of final product so that quantity demanded for final product is equal to quantity demanded for intermediate product. 
The $S$ 's cost of production is linear in output $q$ and its marginal cost of production $c_{S} \geq 0$ is constant per output. The marginal cost can be reduced by the lean activity carried out by the manufacturer in the downstream. We assume that lean activity related to process innovation program can create a synergy in the supply chain so that supplier's marginal cost of production can also reduce linearly: the cost per unit can decrease from $c_{S}$ to $c_{S}-b_{S}$, where $b_{S}$ is positive. The same discussion we have had for $M$ is also valid

for $S$, thus we will additionally evaluate the case in which $b_{S}<0$ as well. Note that the implications of a process innovation program on $S^{\prime}$ 's cost function does not depend on the amplitude of the $M$ 's investments but it is rather a fact that depends on the innovation type. Therefore, in the presence of process innovation its production cost function becomes

$$
C_{S}(q)=\left(c_{S}-b_{S}\right) q
$$

$S$ maximizes its profit function to choose its wholesale price:

$$
\max _{w} \Pi^{S}=\underbrace{q(.)\left(w-c_{S}-b_{S}\right)}_{\text {Forward profit }}
$$

The above assumed functional forms including linear and quadratic cost functions are commonly employed in the literature (e.g., Savaskan et al. (2004), Genc and Zaccour (2013), Genc (2017)) as they are tractable and have support in real industries.

Definition 1: If innovation-led lean programs impacting the production costs (that is, process innovation effect) reduces the marginal cost of production so that $b_{S}>0$ and $b_{M}>0$, then it is called "process innovation lean". If the lean activity only impacts demands and returns (that is, demand and sustainability) so that $\sigma, \eta>0$ and $b_{S}=0=b_{M}$, then it is called "strategic lean".

\section{Stackelberg Competition with innovation-led lean programs}

$S$ is a chain leader who takes consumer and manufacturer behaviors into account before it chooses its wholesale price. Given the demand for its final product, the firms' profit functions are:

$$
\begin{gathered}
\Pi^{M}(p, L \mid w)=(\alpha-\beta p+\sigma L)\left(p-w-c_{M}+b_{M} L\right)-L^{2} / 2+(\theta-\eta L) \Delta_{M} \\
\Pi^{S}=(\alpha-\beta p(w)+\sigma L(w))\left(w-c_{S}+b_{S}\right)
\end{gathered}
$$

The next proposition characterizes the equilibrium strategies.

Proposition 1 (Strategic lean and process innovation lean): In the presence of innovation-led lean programs 
aiming at responsiveness, process innovation and sustainability outcomes, the Stackelberg equilibrium strategies in the CLSC are:

$$
\begin{aligned}
p & =\frac{K_{1} K_{2}+K_{3} K_{4}+\left(\beta K_{3}-\sigma K_{1}\right)\left[\left(c_{S}-b_{S}\right) K_{6}-2 K_{5}\right] / 2 K_{6}}{2 \beta K_{3}-K_{1}^{2}} \\
L & =\frac{K_{1} K_{4}+2 \beta K_{2}+\beta\left(K_{1}-2 \sigma\right)\left[\left(c_{S}-b_{S}\right) K_{6}-2 K_{5}\right] / 2 K_{6}}{2 \beta K_{3}-K_{1}^{2}} \\
w & =\frac{\left(c_{S}-b_{S}\right) K_{6}-2 K_{5}}{2 K_{6}}
\end{aligned}
$$

where $K_{1} \equiv \sigma-\beta b_{M}, K_{2} \equiv-c_{M} \sigma+\alpha b_{M}-\eta \Delta_{M}, K_{3} \equiv 1-2 \sigma b_{M}, \quad K_{4} \equiv \alpha+\beta c_{M}$, and $K_{5} \equiv$ $\alpha-\beta \frac{K_{1} K_{2}+K_{3} K_{4}}{2 \beta K_{3}-K_{1}^{2}}+\sigma \frac{\left(K_{1} K_{4}+2 \beta K_{2}\right)}{2 \beta K_{3}-K_{1}^{2}}$, and $K_{6} \equiv \frac{\sigma \beta\left(K_{1}-2 \sigma\right)}{2 \beta K_{3}-K_{1}^{2}}-\beta \frac{\beta K_{3}-\sigma K_{1}}{2 \beta K_{3}-K_{1}^{2}}$.

Proof: See the Appendix.

The optimal strategies and the related optimal profits turn out to be very complex, which leads to the notion that studying CLSC with innovation-led lean programs results in highly intractable and complicated decisions. Therefore, we will first examine a benchmark supply chain structure without strategic lean and process innovation innovation-led lean programs. This benchmark model will reduce to a simple closed-supply chain game-theoretic setting, in which there is still forward and backward relations. In this case, the return function in (2) will become $v_{1}=\theta$, demand function in (1) will simplify to $q_{1}(p)=\alpha-\beta p$, where subscript " 1 " implies the full absence of innovation-led lean programs. Consequently, the following parameters will hold $\sigma=\eta=b_{S}=b_{M}=0$ and the cost of lean is zero: $C_{L}(L)=0$. In this benchmark scenario, we obtain the following result.

Corollary 1 (No innovation-led lean programs): In the absence of any lean activity and lean effect, the Stackelberg equilibrium strategies in the closed-loop supply chain framework are

$$
p_{1}=\frac{3 \alpha+\beta\left(c_{S}+c_{M}\right)}{4 \beta} \text { and } w_{1}=\frac{\alpha+\beta\left(c_{S}-c_{M}\right)}{2 \beta}
$$

Proof: See the Appendix.

Without lean activity the CLSC undermines the environment because the lower quality of products will induce consumers to return products earlier. Note that in the model the relation $\alpha>\beta\left(c_{S}+c_{M}\right)$ must hold because $w_{1}-c_{S}>0$, that is $S$ earns positive profit. We then obtain classical results in economics: the wholesale price decreases in $M^{\prime}$ 's cost. That is $\partial w_{1} / \partial c_{M}<0$. This is because increase in $c_{M}$ naturally raises retail price $p_{1}$ and lowers quantities. To offset this, supplier has to reduce its wholesale price $w_{1}$. Also, increasing cost causes both firms to increase their own prices. That is $\partial w_{1} / \partial c_{S}>0$ and $\partial p_{1} / \partial c_{M}>0$. 
Furthermore, growth in demand benefits both firms as they can raise their own prices to increase profits. That is $\partial w_{1} / \partial \alpha>0$ and $\partial p_{1} / \partial \alpha>0$.

Analytic comparison of supply chain outcomes under innovation-led lean programs (Proposition 1) to the ones under no lean program (Corollary 1) is a daunting task due to the large number of parameters and their involved relations as expressed in Proposition 1. Therefore, we will compute the profits, prices, and outputs numerically. However, in the following section, we will be able to draw some analytic results when we separately examine the impact of each type of lean activity on the supply chain performance.

In Figure 1 we calibrate the model on $(\alpha, \beta)$ and $\left(c_{S}, c_{M}\right)$ spaces to investigating the optimal profits under these two structures. These are the two possible spaces as the Corollary 1 is defined on these four parameters. We find that both firms are better off under lean activities. Observe that the profits are nonlinear in demand coefficients $\alpha, \beta$ and linear in the marginal costs of production $c_{S}, c_{M}$.

\section{$<$ Insert Figure $1>$}

In Figure 2, the equilibrium wholesale and retail prices are calibrated over the same spaces. We observe that wholesale prices always compare $w_{1}>w$, thus wholesale prices are lower under innovation-led lean programs. The intuition for this result is that supplier also benefits from the cost reduction due to the process innovation efforts of the manufacturer and faces a high demand for its product shown in the following figure. For a large parameter region the retail prices compare $p>p_{1}$, that is retail prices are higher under the lean practices. However, in the $(\alpha, \beta)$ space for a small parameter region in which $\alpha$ is very low (that is market is small or demand is low) and $\beta$ is large (that is consumers are aggressive to price increases or price elasticity of demand is high) then we find that retail prices can be lower under innovation-led lean programs $\left(p<p_{1}\right)$. Consequently, consumers can pay a lower or a higher price when they would like to purchase a lean and a sustainable product.

$$
<\text { Insert Figure } 2>
$$

In Figure 3 the equilibrium sales are calibrated over the two spaces. Sales are always higher in the presence of innovation-led lean programs: $q>q_{1}$. As expected the sales are nonlinear in the demand parameters. The economic reason for this result is that consumer utility increases in lean because consumer demand shifts up as a result of innovation-led lean programs for any given level of the final product price.

$$
<\text { Insert Figure } 3>
$$

As a result, based on the calibrations we find that both firms are better off under the lean programs. Consumers also prefer innovation-led lean programs as they increase their consumption of the lean products. 
Consumers buy more and may pay less. On the other hand when market expands, consumers pay a high price because they know that lean investments are costly (Eq. 4), more consumers buy the lean product, and their utilities also increase in greenness level of the product.

In the next section we will expand the benchmark model in Corollary 1 by examining the contribution of each lean activity (strategic lean vs. process innovation lean) to the CLSC performance and sustainability. This may facilitate better understanding of implications of the complete model solution in Proposition 1 which embeds both types of lean programs.

\section{Impact of innovation-led lean programs}

We will examine impact of the two innovation-led lean programs (strategic lean and process innovation lean) on the CLSC game-theoretic outcomes separately.

\subsection{The impact of Strategic innovation-led lean programs}

We now focus on the sole impact of strategic innovation-led lean programs, thus demand (responsiveness) and return (sustainability) parameters $\sigma$ and $\eta$ are positive while we impose that $b_{S}=b_{M}=0$. With these assumptions, the firms' profit functions become

$$
\begin{gathered}
\Pi_{2}^{M}\left(p_{2}, L_{2} \mid w_{2}\right)=\left(\alpha-\beta p_{2}+\sigma L_{2}\right)\left(p_{2}-w_{2}-c_{M}\right)-L_{2}^{2} / 2+\left(\theta-\eta L_{2}\right) \Delta_{M} \\
\Pi_{2}^{S}\left(w_{2} \mid p_{2}\right)=\left(\alpha-\beta p_{2}+\sigma L_{2}\right)\left(w_{2}-c_{S}\right),
\end{gathered}
$$

where subscript "2" refers to strategic lean. $S$ moves first to optimally choose its wholesale price and then $M$ moves to maximize its profit to choose retail price and the lean investments. The solution of this CLSC game-theoretic approach leads to the following result.

Proposition 2 (Strategic lean): When $M$ implements strategic innovation-led lean programs only, the Stackelberg equilibrium strategies in the CLSC are

$$
\begin{aligned}
p_{2} & =\frac{\left(\alpha-\sigma \eta \Delta_{M}\right)\left(3 \beta-\sigma^{2}\right)+\beta\left(\beta-\sigma^{2}\right)\left(c_{S}+c_{M}\right)}{2 \beta\left(2 \beta-\sigma^{2}\right)} \\
L_{2} & =\frac{\sigma\left(\alpha-\beta\left(c_{S}+c_{M}\right)\right)+\left(\sigma^{2}-4 \beta\right) \eta \Delta_{M}}{2\left(2 \beta-\sigma^{2}\right)} \\
w_{2} & =\frac{\alpha-\beta\left(c_{M}-c_{S}\right)-\sigma \eta \Delta_{M}}{2 \beta}
\end{aligned}
$$


Proof: See the Appendix.

To assess the value added of sustainability efforts in this supply chain, we will compare the results in Proposition 2 to the ones in Corollary 1. We obtain the following result.

Proposition 3: The presence of a strategic effect leads to lower wholesale prices but higher retail prices relative to the benchmark case. That is $w_{2}<w_{1}$ and $p_{2}>p_{1}$.

Proof: See the Appendix.

This result shows that consumers have to pay a higher price to obtain a superior product which also has environmental benefits. Alternatively lean efforts are costly to the manufacturer who will reflect this cost onto the price. While the adoption of lean is a reason for $M$ to increase its price, both firms will enjoy higher sales (responsiveness). On the other hand, there will be less returns under lean investments. Consequently, consumers will consume more, hold on more of their newly purchased products, but have to pay a high price. Proposition 3 suggests that lean activity could be a socially desirable outcome as consumers demand more of the lean product and return less.

Claim 1: $S$ is better off under the strategic innovation-led lean programs while $M$ is better off only when the lean investment is "sufficiently low" and/or the marginal value of collection is "sufficiently high".

While it is algebraically cumbersome and non-tractable to compare the profits in Corollary 1 (no lean) versus Proposition 2 (strategic lean) as we have 10 parameters entering into the equilibrium strategies, we compare the profits of both firms numerically in the following example.

Example 1: Assume the following parameter values which are feasible and obeying the equilibrium conditions. Let $\alpha=5, \beta=1 ; \sigma=0.5 ; c_{M}=0.1 ; c_{S}=0.05 ; b_{M}=0 ; b_{S}=0 ; \theta=0.3 ; \eta=0.2 ;$ and $\Delta_{M}=0.5$. These parameters ensure that prices, outputs, and lean effort are all positive. From Corollary 1 we calculate that wholesale price $w_{1}=2.475$, retail price $p_{1}=3.7875$, quantity demanded $q_{1}=1.2125$. Consequently, S's profit is $\Pi_{1}^{S}=2.9403$ and $M$ 's profit is $\Pi_{1}^{M}=1.62016$. From Proposition 2 we calculate that wholesale price $w_{2}=2.45$, retail price $p_{2}=3.9214$, lean effort $L_{2}=0.5857$, quantity demanded $q_{2}=1.71429$. Consequently, $S$ 's profit is $\Pi_{2}^{S}=3.291$ and $M$ 's profit is $\Pi_{2}^{M}=1.892$.

First, we observe $S$ 's profits are larger than $M$ 's profits due to the Stackelberg game-theoretic structure and the fact that it does not incur any cost of lean activity.

Second, this numerical example confirms the theoretical prediction $w_{2}<w_{1}$ and $p_{2}>p_{1}$.

Third, we observe that $S$ benefits from a strategic effect entailed by lean investments, as $q_{2}>q_{1}$ and $\Pi_{2}^{S}>\Pi_{1}^{S}$. 
Fourth, $M$ 's profit is also higher as $\Pi_{2}^{M}>\Pi_{1}^{M}$, given that its sales and retail price go up $\left(q_{2}>q_{1}\right.$ and $\left.p_{2}>p_{1}\right)$. The fact that its output and price are higher implies that $M$ would increase its profit $\left(\Pi_{1}^{M}\right)$. Although $M$ bears the cost of lean programs, there is a room for further profit increase either by increasing its marginal value of returns $\left(\Delta_{M}\right)$ or by reducing its cost of lean activity $(C(L))$. To facilitate this $M$ would need to engage in further innovation-led lean programs such as better use of returned products in the remanufacturing process or offering lower rebates for returned products so as to make collections worthwhile. In addition, the cost of lean could be reduced through other innovation-led lean programs such as training, learning, or efficiency. Consequently, one can easily set up another example to obtain that $M$ 's profit would be even higher under innovation-led lean programs when higher $\Delta_{M}$ and/or lower $C(L)$ were chosen.

Consequently, innovation-led lean programs aiming sustainability can be beneficial for all parties $(C, M, S)$ as well as government who aims to lower emissions and enhance air quality expressed in (2). Therefore, innovation-led lean programs with sustainability program designed in this model can be a welfare-maximizing strategy for the society.

\subsection{The Impact of Process Innovation innovation-led lean programs}

We now assess the sole impact of process innovation effect entailed by innovation-led lean programs, thus $\sigma$ and $\eta$ are both zero and process innovation parameters $b_{S}$ and $b_{M}$ are positive. Under such circumstances, the firms' objective functions become:

$$
\begin{gathered}
\Pi_{3}^{M}\left(p_{3} \mid w_{3}\right)=\left(\alpha-\beta p_{3}\right)\left(p_{3}-w_{3}-c_{M}+b_{M} L_{3}\right)-L_{3}^{2} / 2+\theta \Delta_{M} \\
\Pi_{3}^{S}\left(w_{3} \mid p_{3}\right)=\left(\alpha-\beta p_{3}\right)\left(w_{3}-c_{S}+b_{S}\right),
\end{gathered}
$$

where subscript " 3 " refers to the implementation of innovation-led lean programs to induce process innovation effects. The solution of this CLSC game-theoretic framework leads to the following result.

Proposition 4 (Process innovation lean): When $M$ executes innovation-led lean programs to gain on the process innovation effect, the Stackelberg equilibrium strategies in the CLSC are

$$
\begin{aligned}
p_{3} & =\frac{\alpha\left(3-2 \beta b_{M}^{2}\right)+\beta\left(c_{S}+c_{M}-b_{S}\right)}{2 \beta\left(2-\beta b_{M}^{2}\right)} \\
L_{3} & =b_{M} \frac{\alpha-\beta\left(c_{S}+c_{M}-b_{S}\right)}{2\left(2-\beta b_{M}^{2}\right)} \\
w_{3} & =\frac{\alpha+\beta\left(c_{S}-c_{M}-b_{S}\right)}{2 \beta}
\end{aligned}
$$

Proof: See the Appendix. 
To assess the impact of process innovation, we will compare the equilibrium strategies in Proposition 4 to the ones in Corollary 1. We obtain the following result.

Proposition 5 With the implementation of a process innovation-led lean programs, the wholesale and retail prices are lower than the ones in the benchmark case.

Proof: See the Appendix.

When $M$ carries out a lean practices to exploit process innovation effects, the process innovation decreases the production cost, and therefore firms will decrease their prices. This result is straightforward. However, it is interesting to see that although $M$ carries out the process innovation its impact on the price differential is mainly determined by the change in $S$ 's marginal production cost $b_{S}$. That is $b_{S}$ is a critical parameter in determining the magnitude of $p_{3}-p_{1}$ and $w_{3}-w_{1}$. As it is algebraically non-tractable to contrast the profits in Corollary 1 and Proposition 4 due to the involved relationship between the model parameters and their possible ranges, we compare the profits numerically in the following example.

Example 2: Using the similar parameter values assumed in Example 1, we calculate the chain outcomes with and without process innovation. Assume the following parameter values which are feasible and obeying the equilibrium conditions. Let $\alpha=5, \beta=1 ; \sigma=0 ; c_{M}=0.1 ; c_{S}=0.05 ; b_{M}=0.05$; $b_{S}=0.01 ; \theta=0.3 ; \eta=0 ;$ and $\Delta_{M}=0.5$. These parameters ensure that prices, outputs, and lean effort are all positive. When there is no process innovation nor any lean activity (Corollary 1) the equilibrium outcomes in the closed-loop supply chain are: wholesale price $w_{1}=2.475$, retail price $p_{1}=3.7875$, quantity demanded $q_{1}=1.2125$, supplier's profit $\Pi_{1}^{S}=2.9403$, and manufacturer's profit $\Pi_{1}^{M}=1.62016$. When $M$ engages in process innovation (Proposition 4) the market outcomes are: wholesale price $w_{3}=2.47$, retail price $p_{3}=3.7835$, lean effort $L_{3}=0.06083$, quantity demanded $q_{3}=1.2165$, supplier's profit $\Pi_{3}^{S}=2.9561$, and manufacturer's profit $\Pi_{3}^{M}=1.6281$.

We observe that lean process innovation benefits all CLSC members. Consumers face lower price, higher consumption, and therefore higher surplus. Also, $S$ greatly benefits from $M$ 's process innovation which reduces $S$ 's cost and increases its sales and profits. $S$ is a free-rider in this supply chain in the sense that it benefits from $M$ 's innovation efforts without incurring a cost. $M$ also decreases its production cost and increases its sales and profits.

Example 3: Using the similar parameter values assumed in Example 2, we calculate the chain outcomes while considering negative process innovation effects. Thus, we impose that $b_{M}=-0.05$ and $b_{S}=$ -0.01 . These parameter values lead to negative lean efforts and do not ensure that prices, outputs and 
profits are positive. Consequently, the sole presence of a process innovation effect that deteriorates the production cost leads to an unfeasible solution.

The outcomes from Example 3 reveal a clear cut result: Firms should not engage in innovation-led lean programs when there are negative implications for the operations (production costs) while strategic effects are fully missed. Put differently, if consumers do not recognize the added-value of implementing lean practices, firms should abandon the idea of being leaner when the process innovation effect is negative and find alternative ways to make their business more profitable.

Note that the profit improvement that the firms obtain with the positive process innovation lean program is lower than that obtained through the strategic lean program (Example 1 vs Example 2). Then, we will compare contrast the profits under the two lean programs to better understand the best option.

\subsection{Strategic Lean vs. Process innovation-led lean programs}

In this section, we numerically compare the findings in Propositions 2 and 4 to see how strategies and profits change with respect to lean programs. We focus on the key parameters $\sigma, \eta$, and $b_{M}$ while fixing $b_{S}=0.01 b_{M}$ to capture its effect. Note that we disregard the case when the effect of process lean can be negative as this is not feasible (see Example 3). Our simulations are displayed in Figure 4.

$<$ insert Figure 4>

From Figure 4, the following results are derived:

1. When CLSCs use innovation-led lean programs to exploit economic and the sustainable benefits, namely, sales increase and return developments, the price will be larger than the case in which lean activities only provide some process innovation effect. This result mainly depends on the role that innovation-led lean programs play in demand function: when consumers perceive the contribution provided by the CLSCs, they are willing to purchase the product, independent of the price. This is in line with the idea that consumers are environmentally conscious and are willing to pay a larger price for superior products obtained through lean practices. Interestingly, there is only a very small region, $\Sigma_{1}$, in which the price in the process innovation lean case will be higher. For small values of $\sigma$ and $b_{M}$, consumers tend to hold on to the product which allows $M$ to charge a larger price.

2. $S$ will charge a larger wholesale price in the strategic lean case for combinations of $\sigma$ and $\eta$, while $b_{M}$ will not play any role. De-facto, $S$ disregards the $M$ 's operational benefits for choosing the wholesale price. When the contribution of lean activities on demand and returns is high, it will charge a lower wholesale price to induce $M$ to lower retail price and increase sales. 
3. The innovation-led lean programs are larger under strategic lean only in a small region, namely $\Sigma_{2}$, in which the contribution to the demand is sufficiently large (high $\sigma$ ), the penalty associated with the returns is minimal (low $\eta$ ), and the operational benefits are low (low $b_{M}$ ). Clearly, when the contribution of innovationled lean programs to the demand is minimal, the CLSC has a lower incentive to invest in innovation-led lean programs because the sales will not react to the investments. In such a case, it is convenient to invest more in lean only when consumers are able to perceive the contribution of the CLSC activities. Second, when consumers keep their products and reduce their returns, the CLSC has no incentive to invest more in lean. Finally, when the operational benefits are large, the CLSC would concentrate on the innovation-led lean programs that aim at exploiting the process innovation potential, even if consumers do not value it.

4. In the analysis of the profits, one can see that large values of $\sigma$ dominate the effects of the other parameters. Thus, it will be sufficient that consumers respond positively to innovation-led lean programs by purchasing more so that both firms will push for the strategic lean. When $\sigma$ takes low values, $\eta$ and $b_{M}$ play an important role. Intuitively, the larger the operational benefits, the larger the firm incentives for adopting a process innovation lean. Differently, $\eta$ plays a different role in the firms' profits: increasing consumers' attitudes in retaining their products instead of returning them makes $M$ always better off and $S$ worse off under the strategic lean programs. This is due to the fact that $M$ 's cost of lean is low and therefore it generates larger profits

5. While there is another region, $\Sigma_{3}$, in which firms have divergent preferences, in the remaining regions pursuing either a strategic lean or a process innovation lean will be Pareto-improvement.

\section{Vertical Integration with innovation-led lean programs}

We now consider the case of a CLSC structure in which the firms integrate vertically. The vertical integration (VI) is another benchmark for comparing supply chains because it allows the firms to eliminate all internal inefficiencies resulting from the supply chain relationships and contracts. The CLSC objective function under VI will be then given by:

$$
\Pi^{V I}=\Pi^{M}+\Pi^{S}=\left(\alpha-\beta p+\sigma L_{M}\right)\left(p-c_{M}-c_{S}+b_{S}+b_{M} L_{M}\right)-\frac{L^{2}}{2}+(\theta-\eta L) \Delta_{M}
$$

Using the same procedure we have used for the decentralized case, we obtain the optimal strategies and profits for the vertical integration case, which are summarized in the proposition below.

Proposition 6: In the presence of both strategic and process innovation lean programs, the equilibrium 
strategies in the VI CLSC are

$$
\begin{aligned}
p^{V I} & =\frac{\left(1-\sigma b_{M}\right)(\alpha+c \beta)+\beta b_{M}\left(\eta \Delta_{M}-\alpha b_{M}\right)-\left(c \sigma+\eta \Delta_{M}\right) \sigma}{2 \beta-\left(\sigma+\beta b_{M}\right)^{2}} \\
L^{V I} & =\frac{\left(\sigma+\beta b_{M}\right)(\alpha-c \beta)-2 \beta \eta \Delta_{M}}{2 \beta-\left(\sigma+\beta b_{M}\right)^{2}}
\end{aligned}
$$

and the profit function is

$$
\Pi^{V I}=\frac{(\alpha-c \beta)^{2}+2 \Delta_{M}\left(\theta\left(2 \beta-\left(\sigma+\beta b_{M}\right)^{2}\right)-\eta\left((\alpha-c \beta)\left(\sigma+\beta b_{M}\right)-\beta \eta \Delta_{M}\right)\right)}{2\left[2 \beta-\left(\sigma+\beta b_{M}\right)^{2}\right]}
$$

Proof: See the Appendix.

When no Lean activity is in place, $\sigma=\eta=b_{M}=b_{S}=0$. Consequently, the previous results become:

Corollary 2: In the absence of any innovation-led lean programs, the VI CLSC equilibrium pricing strategy and profits are:

$$
p_{1}^{V I}=\frac{\alpha+\left(c_{M}+c_{S}\right) \beta}{2 \beta} \text { and } \Pi_{1}^{V I}=\frac{\left(\alpha-\left(c_{M}+c_{S}\right) \beta\right)^{2}+4 \theta \beta \Delta_{M}}{4 \beta}
$$

Proof: Plug $\sigma=\eta=b_{M}=b_{S}=0$ into Eqs. (24) and (26) to obtain the results in the proposition. The implementation of innovation-led lean programs leads the VI CLSC profits to increase as $\Pi^{V I}-\Pi_{1}^{V I}=$ $\frac{\left((\alpha-c \beta)\left(\sigma+\beta b_{M}\right)-2 \beta \eta \Delta_{M}\right)^{2}}{4 \beta\left[2 \beta-\left(\sigma+\beta b_{M}\right)^{2}\right]}>0$.

We will now look into the CLSC problem of investing in innovation-led lean programs to push either strategic effect or process innovation effect. We will treat the to cases separately to better understand the relationships between the policies.

\subsection{The Impact of Strategic Lean Programs}

We first focus on the impact of strategic lean. The core part of our model that links to sustainability is captured by means of $\sigma$ and $\eta$, while $b_{M}=0$ and $b_{S}=0$. Thus, we isolate the problem to the trade-off between demand and returns. The CLSC's objective function becomes:

$$
\Pi_{2}^{V I}=\Pi_{2}^{M}+\Pi_{2}^{S}=(\alpha-\beta p+\sigma L)\left(p-c_{M}-c_{S}\right)-\frac{L^{2}}{2}+(\theta-\eta L) \Delta_{M}
$$

where we use the subscript "2" to identify this special case. 
Proposition 7: Under strategic lean, the VI CLSC equilibrium strategies of price and lean efforts are

$$
\begin{aligned}
p_{2}^{V I} & =\frac{\left(\alpha+\beta\left(c_{M}+c_{S}\right)-\sigma\left(\sigma\left(c_{M}+c_{S}\right)+\eta \Delta_{M}\right)\right)}{2 \beta-\sigma^{2}} \\
L_{2}^{V I} & =\frac{\left(\sigma\left(\alpha-\beta\left(c_{M}+c_{S}\right)\right)-2 \beta \eta \Delta_{M}\right)}{2 \beta-\sigma^{2}}
\end{aligned}
$$

and the optimal profit is

$$
\Pi_{2}^{V I}=\frac{\left(\alpha-\left(c_{M}+c_{S}\right) \beta\right)^{2}+2 \Delta_{M}\left(\theta\left(2 \beta-\sigma^{2}\right)-\eta\left(\left(\alpha-\left(c_{M}+c_{S}\right) \beta\right) \sigma-\beta \eta \Delta_{M}\right)\right)}{2\left[2 \beta-\left(\sigma+\beta b_{M}\right)^{2}\right]}
$$

Proof: See the Appendix.

Interestingly, one can see that $\frac{\partial p\left(L_{M}\right)}{\partial L_{M}}=\frac{\sigma}{2 \beta}>0$ always holds. Consequently, when innovation-led lean programs do not provide any type of process innovation benefits, the CLSC's decisions are less complex. In particular, any time the innovation-led lean programs increase, the CLSC can also charge a larger price. One can see that $\frac{\partial L_{M}(p)}{\partial p}=\sigma>0$ always holds, thus reinforcing the previous statement. The CLSC will set the optimal strategies for solving the trade off entailed by $\sigma$ and $\eta$.

Lemma 1: The CLSC solves the trade-off between demand and returns given by $\frac{\partial \Pi_{2}^{V I}}{\partial \eta}=-\frac{\Delta_{M}\left(\sigma\left(\alpha-\beta\left(c_{M}+c_{S}\right)\right)-2 \beta \eta \Delta_{M}\right)}{\left(2 \beta-\left(\sigma+\beta b_{M}\right)^{2}\right)}<$ 0 and $\frac{\partial \Pi_{2}^{V I}}{\partial \sigma}=\frac{N U M\left\{\Pi_{2}^{V I}\right\}\left(\sigma+\beta b_{M}\right)}{\left(\left(2 \beta-\left(\sigma+\beta b_{M}\right)^{2}\right)\right)^{2}}+\frac{\Delta_{M}\left(2 \theta \sigma+\eta\left(\alpha-\beta\left(c_{M}+c_{S}\right)\right)\right)}{\left(2 \beta-\left(\sigma+\beta b_{M}\right)^{2}\right)}>0$.

Solving the previous trade-off makes the VI CLSC always willing to commit more efforts on lean activities. To appreciate the impact of lean on sustainability we need to compare the results in Proposition 6 with Proposition 7. To do that, it will be sufficient to understand how the strategies and the profits in Proposition 6 change according to $b_{M}$ and $b_{S}$.

Proposition 8: The implementation of strategic innovation-led lean programs leads to lower prices and higher lean efforts and profits.

Proof: It suffices to compute the derivatives of $p^{V I}, L^{V I}$, and $\Pi^{L I}$ as displayed in Proposition 6 to check that:

- $\frac{\partial p^{V I}}{\partial b_{M}}=\frac{\left(-\sigma\left(\alpha+\left(c_{M}+c_{S}-b_{S}\right) \beta\right)+\beta\left(\eta \Delta_{M}-2 \alpha b_{M}\right)\right)}{2 \beta-\left(\sigma+\beta b_{M}\right)^{2}}+\frac{2 \beta\left(\sigma+\beta b_{M}\right) N U M\{p\}}{\left(2 \beta-\left(\sigma+\beta b_{M}\right)^{2}\right)^{2}} \gtreqless 0$ for $b_{M} \lesseqgtr \bar{b}_{M}$ (numerically derived) and $\frac{\partial p^{V I}}{\partial b_{S}}=-\frac{\sigma^{2}-\beta\left(1-\beta b_{M}\right)}{2 \beta-\left(\sigma+\beta b_{M}\right)^{2}}<0$,

- $\frac{\partial L^{V I}}{\partial b_{M}}=\frac{\beta\left(\alpha-\left(c_{M}+c_{S}-b_{S}\right) \beta\right)}{2 \beta-\left(\sigma+\beta b_{M}\right)^{2}}+\frac{2 \beta\left(\sigma+\beta b_{M}\right) N U M\left\{L_{M}\right\}}{\left[2 \beta-\left(\sigma+\beta b_{M}\right)^{2}\right]^{2}}>0$ and $\frac{\partial L^{V I}}{\partial b_{S}}=\frac{\beta\left(\sigma+\beta b_{M}\right)}{2 \beta-\left(\sigma+\beta b_{M}\right)^{2}}>0$

- $\frac{\partial \Pi^{V I}}{\partial b_{M}}=\frac{-2 \Delta_{M} \beta\left(2 \theta\left(\sigma+\beta b_{M}\right)+(\alpha-c \beta) \eta\right)}{2\left[2 \beta-\left(\sigma+\beta b_{M}\right)^{2}\right]}+\frac{\beta\left(\sigma+\beta b_{M}\right) N U M\left\{\Pi^{S C}\right\}}{\left[2 \beta-\left(\sigma+\beta b_{M}\right)^{2}\right]^{2}}>0$ and $\frac{\partial \Pi^{V I}}{\partial b_{S}}=\frac{\beta\left(\alpha-\beta\left(c_{M}+c_{S}-b_{S}\right)\right)}{2 \beta-\left(\sigma+\beta b_{M}\right)^{2}}>0$.

Consequently, $p^{V I}-p_{2}^{V I}>0, L^{V I}-L_{2}^{V I}>0$ and $\Pi^{V I}>\Pi_{2}^{V I}$ always hold. 
$<$ insert Figure 5>

CLSCs tend to invest more in innovation-led lean programs which would generate a clear positive effect on responsiveness and sustainability. In sum, when operations is embedded in the CLSC decision of sustainability, the decision maker aims at boosting sales (being more responsive) rather than increasing the returns (being more sustainable). The analysis of the price deserves a special attention. In fact, operational benefits can damage the retail price till a certain point, $\bar{b}_{M}$, and then changing behavior (see Figure 5 ). When the benefits are only marginal, i.e. $b_{M}\left(0, \bar{b}_{M}\right)$, the CLSC attempts to invest in innovation-led lean programs to get such a benefit. Nevertheless, the high investments are also recovered by imposing larger prices because the operational benefits alone are not sufficient to cover that investments. Consequently, the consumers pay larger prices when the operational benefits are only marginal. From a social point of view, the CLSC should then abandon the idea of complementing the sustainability issues with the operational issues. Also, investing more in lean will bring lower returns back, so the CLSC performs low sustainability performance. Clearly, there is a challenging problem of achievements as doing more innovation-led lean programs always increases the profits but also deteriorates responsiveness and sustainability. Nevertheless, when the benefits are sufficiently large, e.g. $b_{M}>\bar{b}_{M}$, the CLSC sets lower prices, thus transferring a part of the operational benefits to the consumers as well.

\subsection{The Impact of Process Innovation innovation-led lean programs}

We now focus on the impact of process innovation, thus disregarding its impact on responsiveness and sustainability. Accordingly, we assume that $\sigma=0$ and $\eta=0$ while $b_{M}>0$ and $b_{S}>0$. We will use the subscript "3" to refer to this setting. The VI CLSC's objective function is:

$$
\Pi^{V I}=\Pi^{M}+\Pi^{S}=(\alpha-\beta p)\left(p-c+b_{M} L_{M}\right)-\frac{L_{M}^{2}}{2}+\theta \Delta_{M}
$$

Proposition 9: In the presence of process innovation-led lean programs, the equilibrium strategies in the VI CLSC are

$$
\begin{aligned}
p_{3}^{V I} & =\frac{(\alpha+c \beta)-\alpha b_{M}^{2} \beta}{\beta\left(2-\beta b_{M}^{2}\right)} \\
L_{3}^{V I} & =\frac{b_{M}(\alpha-c \beta)}{\left(2-\beta b_{M}^{2}\right)}
\end{aligned}
$$

and the profit function is

$$
\Pi_{3}^{V I}=\frac{(\alpha-c \beta)^{2}+2 \Delta_{M}\left(\theta \beta\left(2-\beta b_{M}^{2}\right)\right)}{2 \beta\left(2-\beta b_{M}^{2}\right)}
$$


Proof: See the Appendix.

Note that when $b_{M}<0, L_{3}^{V I}<0$ holds; thus, also in the vertical integration scenario, the case when process innovation has negative implications for the production process is not feasible without any strategic lean effect.

Proposition 10: The process innovation-led lean programs lead to lower prices as well as higher lean efforts and profits.

Proof: It suffices to compute the derivatives of $p_{3}^{V I}, L_{3}^{V I}$, and $\Pi_{3}^{V I}$ with respect to $b_{M}$ and $b_{S}$ to check that:

- $\frac{\partial p_{3}^{V I}}{\partial b_{M}}=\frac{2(c \beta-\alpha) b_{M}}{\left(2-\beta b_{M}^{2}\right)^{2}}<0$ and $\frac{\partial p_{3}^{V I}}{\partial b_{S}}=\frac{1}{2-\beta b_{M}^{2}}<0$

- $\frac{\partial L_{3}^{V I}}{\partial b_{M}}=\frac{(\alpha-c \beta)\left(\beta b_{M}^{2}+2\right)}{\left(2-\beta b_{M}^{2}\right)^{2}}>0$ and $>\frac{\partial L_{3}^{V I}}{\partial b_{S}}=\frac{\beta b_{M}}{2-\beta b_{M}^{2}}>0$;

- $\frac{\partial \Pi_{3}^{V I}}{\partial b_{M}}=\frac{(\alpha-c \beta)^{2} b_{M}}{\left(2-\beta b_{M}^{2}\right)^{2}}>0$ and $>\frac{\partial \Pi_{3}^{V I}}{\partial b_{S}}=\frac{(\alpha-\beta c)}{2-\beta b_{M}^{2}}>0$.

Our findings are aligned with the literature (e.g., Kobayashi, 2015) according to which process innovation investments generate a marginal cost reduction and, consequently, a lower price. Our results are conformable with this literature and confirm that the findings are also valid in the context of lean activities when the lean aims at operational targets. CLSCs can find investing in innovation-led lean programs convenient when the price is the sole variable/factor in demand function, such that a price reduction leads to high benefits.

\subsection{Strategic lean vs. Process innovation lean in VI CLSC}

We now compare the results in Propositions 7 and 9 to check whether CLSCs should push more for strategic lean or process innovation lean. We carry out the comparison numerically due to the complexity of the relationships, as displayed in Figure 6.

$$
<\text { insert Figure 6> }
$$

From Figure 6, the following results can be derived:

1. The wholesale prices under the strategic lean are almost always higher than the ones under the process innovation lean. The region in which the price under process innovation lean is large tends to decrease because both the marginal benefit of collection and the sustainability benefit increase. Thus, when firms are integrated the compensation effect between lean activities and pricing strategies is more evident in the demand function.

2. $M$ will invest more in strategic lean than in process innovation lean independent of the double marginalization effect. Interestingly, the VI CLSC will have the same attitude of investing in innovation-led lean programs as the decentralized CLSC, although the double marginalization effect is mitigated. 
3. Regarding the economic performance, we can see that the region $\Omega_{2}$ in which the CLSC would focus on strategic lean programs is very large. This region mainly depends on the contribution of innovation-led lean programs on sales, $\sigma$. When this is very large, the CLSC finds always convenient to invest in innovationled lean programs that aim at acknowledging consumers on the environmental orientation that the CLSC undertakes. In all other cases, the innovation-led lean programs should aim at increasing the internal efficiency exemplified by lower marginal production costs.

Lemma 2: Profits in VI compare $\Pi^{V I}>\Pi_{2}^{V I}>\Pi_{3}^{V I}>\Pi_{1}^{V I}$ inside $\Omega_{2}$, and $\Pi^{V I}>\Pi_{3}^{V I}>\Pi_{2}^{V I}>\Pi_{1}^{V I}$ outside $\Omega_{2}$.

Finally, we can see that when the SC can exploit all positive forces of its business, that is, large impact on sales, large benefits in operations and marginal negative impact on returns (e.g., $\sigma=0.8, \eta=0.01$ and $\left.b_{M}=b_{S}=0.3\right)$ the CLSC is always economically better-off. The latter corresponds to the case $\Pi^{V I}$, thus, we can conclude that CLSCs always prefer to invest in innovation-led lean programs that contribute to both sales developments through responsiveness, sustainability through returns, and operational efficiency through process innovation. Therefore, when there is a trade-off among all forces, the CLSC should prefer strategic lean as long as responsiveness is high; otherwise, it should choose process innovation lean when it is positive.

\section{Special case: Strategic Lean vs. Negative process innovation-led lean programs.}

In this section, we aim at developing a special case when process innovation lean has negative effects on the marginal production cost while the strategic effect is still present. From Example 3, we learn that having no strategic lean $(\eta=0$ and $\sigma=0)$ and having negative impact of lean on operations $\left(b_{M}<0\right.$ and $\left.b_{S}<0\right)$ is not a feasible scenario. Thus, we deal with a situation where the strategic lean exists $(\eta>0$ and $\sigma>0)$ and process innovation lean implies negative effects on the marginal production cost $\left(b_{M}<0\right.$ and $\left.b_{S}<0\right)$. Indeed, the optimal strategies and profits follow exactly the procedure described in Proposition 1, with the difference that $b_{M}<0$ and $b_{S}<0$. As we have done previously, we focus on the key parameters $\sigma, \eta$, and $b_{M}$ while fixing $b_{S}=0.01 b_{M}$, and compare the firms' profits in this special case with the firms' profits resulting from Corollary 1. We refer to $\bar{\Pi}^{M}$ and $\bar{\Pi}^{S}$ as the firms' profits in the special case with $b_{M}<0$ and $b_{S}<0$.

$<$ insert Figure 7>

Accordingly, we can see that both firms' profits gets reduced by the negative process effects: The higher $b_{M}$ is, the lower the convenience of pursuing innovation-led lean programs. Although this negative effect 
is present for the whole CLSC, for $S$ it shows a higher region of parameters inside which negative process innovation effect considerably reduces profits when adoption innovation-led lean programs. Consequently, the presence of a high strategic effect is prerequisite to overcome the issues linked to negative process innovation effects entailed by innovation-led lean programs.

Similarly, we can compare the vertical integration solution with $\eta, \sigma>0$ and $b_{M}, b_{S}<0$ to Corol-

lary 2. The vertical integration profits in this special case are $\bar{\Pi}^{V I}$. Then, we compute $\bar{\Pi}^{V I}-\Pi_{1}^{V I}=$ $\frac{\left((\alpha-c \beta)\left(\sigma+\beta b_{M}\right)-2 \beta \eta \Delta_{M}\right)^{2}}{4 \beta\left(2 \beta-\left(\sigma+\beta b_{M}\right)^{2}\right)}$, where $b_{M}<0$ and $b_{S}<0$.

Example 4: Using similar parameter values assumed in Example 2, we will calculate the chain outcomes with positive strategic lean and negative process lean and compare it to the absence of lean. In fact, differently from Example 2, we assume that process innovation is detrimental for profit margins. Thus, we impose that $b_{M}=-0.05$ and $b_{S}=-0.01$. These parameter values give a $\bar{\Pi}^{V I}-\Pi_{1}^{V I}=0.242$, comparatively to the larger amount $\Pi^{V I}-\Pi_{1}^{V I}=0.416$.

Consequently, we find that even if firms in the CLSC are fully integrated, the absence of lean process benefits plays an important role, leading to a reduction of almost half of the economic benefits. Notwithstanding, when firms experience negative impact of innovation-led lean programs on their production processes, they should sponsor their strategic lean effect. If strategic lean effects are not present, firms should abandon the idea of investing in innovation-led lean programs when those have a detrimental effect on the production cost.

\section{Discussion and managerial implications}

Our findings are relevant not only for the research developments on innovation-led lean programs but also for many real-life situations. Thus, the results of this research can be used as benchmarks by the managers who would understand how to implement innovation-led lean initiatives to achieve both strategic and process innovation benefits and sustainability in CLSCs. In this section, we aim to summarize our findings, link them to some real firms and offer some managerial insights.

First, when positive strategic and process innovation effects characterize innovation-led lean venture, firms should always pursue those programs to achieve sustainability targets, improve their responsiveness and create efficiency over the production process. For example, Coca-Cola has committed some lean practices with its stakeholders to reduce the water utilization, the packaging, the carbon footprint, and sustain the agriculture (www.cocacola.com). With these practices, Coca-Cola recycles $75 \%$ of the cans and the packaging introduced in the market. Bosch has recently launched the program Bosch 
eXchange, according to which an CLSC allows reusing industrial components. Bosch aimed at introducing some new (green) lean practices for reduction of energy, raw materials, and CO2. This lean program leads to sustainability, through repairing more than $50 \%$ of newly sold goods, as well as production process savings in $90 \%$ of energy and $50 \%$ of CO2.

Second, when innovation-led lean programs are not characterized by any strategic effect, CLSCs should take careful considerations before implementing those programs. In fact, they should be pursued only when the production process obtains benefits from such practices. In all other cases, firms are advised to look for alternative ways of creating value within their CLSC and implement some alternative programs oriented towards increasing the strategic effect. When comparing innovation-led lean programs, firms should always evaluate the contribution of strategic effects, which are more relevant for achieving responsiveness, sustainability and process efficiency. In contrast, innovation-led lean programs based on process innovation should be considered only as secondary programs. This finding is in line with the DellReconnect project, which consists of a partnership with some Goodwill agencies for managing the responsible collection of electronics in the USA (www.dellreconnect.com). While the introduction of these innovation-led lean programs has quite successful (positive process innovation effect), the absence of a social option value (strategic effect) has been shown to be detrimental for Dell's profits (De Giovanni and Ramani, 2017). That is, when consumers cannot understand the collective and environmental benefits created through DellReconnect, lean practices turn out to be environmentally sustainable but marginally attractive from an economic viewpoint. In the textile sector, firms like H\&M, Zara, Prenatal, and Oviesse have adopted new CLSC concepts for collecting the used apparel and reuse them in remanufacturing. Consumers bring their used clothes to a shop and get a rebate. On the one hand, these companies use returns in the production process to save on the virgin material and energy. On the other hand, they reach higher sustainability as a lower amount of used clothes is discharged to the environment. After all, these firms have actively push for the the strategic effect through some rebates (e.g., generating further responsiveness and sales). Our findings show that firms must pursue their actions in this direction, that is, communicating with consumers about the benefits of their green actions, demonstrating their contribution to the environmental preservation through the adoption of lean practices. In this sense, our findings are clearly extendable to other sectors and industries, which are characterized by similar structures. For example, toy, baby care, electronics, automobile, and cement are among the sectors in which managers can apply our findings to target responsiveness, sustainability and process innovation efficiency through innovation-led lean programs.

Third, we advice firms to abandon the idea of being responsive, sustainable and efficient 
through innovation-led lean programs when the strategic effect is not in play and/or lean practices have a negative impact on operations. This is in line with several real cases. For instance, Nebia.com has created a new production shower system by using lean principles in the design phase with the target of reducing the water waste. The adoption of some innovation-led lean programs leads to sustainability as the new concept considerably decreases the water consumption. Nevertheless, the insufficient consumers willingness to change and the negative impact on the production process make the business model marginally appealing (www.nebia.com). The current discussion linked to the abolishment of diesel cars in some capitals (e.g., Rome by 2024) to reduce emissions (McGrath, 2016) induced several car manufacturers to investing in green activities by introducing some new practices. One solution is substituting diesel with electric cars. Nevertheless, consumers can see this jump as very disruptive as electrical cars are more expensive, and do not guarantee the same performance and lifespan. In the health-care sector, the adoption of innovation-led lean programs to reduce the waste, energy and resources can be realized by shifting from an olive-oil soap to a preformulated ingredient (Carrillo et al., 2016). Although this leads to sustainability, process innovation effects are lost while consumers may be reluctant in purchasing the new soap. H\&M (www.h\&m.com) is one of the major founders of the Better Cotton Initiative, developed along with the WWF. The idea behind the initiative is to adopt some lean practices (elimination of waste) to reuse the cotton collected from the used and secondary market and launch a new line of $100 \%$ made of renewable cotton. The major challenge that $\mathrm{H} \& \mathrm{M}$ faces is the cotton extraction, which is very expensive leading to higher production costs. Thus, communication with the market is essential to materialize the benefit of strategic effect; otherwise, sustainability effort along with the negative production process implications make the CLSC unprofitable.

\section{Conclusions, Limitations and Future Directions}

\subsection{Conclusions}

This paper studies several models of CLSC by examining vertical relations between consumers, manufacturer (downstream), and supplier (upstream) in the context of innovation-led lean programs. The latter involves sustainability, responsiveness and process innovations. In these configurations, consumers are sophisticated and respond to innovation-led lean programs. To our knowledge, this is the first paper in the literature investigating innovation-led lean programs within the CLSC context by using a game-theoretic approach.

In a decentralized CLSC, we find that the adoption of innovation-led lean programs is always convenient when containing both a strategic component and a process innovation component. The former includes the consumers' recognition of the CLSC contributions to the environment, exemplified by responsible returns, as 
well as to the sales, by increased responsiveness. The latter refers to innovation-led lean programs that allow the CLSC to improve profit margins by acting on the marginal production cost and taking the form of process innovation. We find that strategic lean provides more favorable outcomes than the process innovation lean programs depending on the consumers' perception of CLSC responsiveness, sustainability, and operational benefits. Our analysis shows that the supplier fully disregards the operational benefits that the manufacturer obtains when charging the wholesale price. Rather, it looks into the lean contribution to sales and returns: when at least one of them is sufficiently large, it will set a larger wholesale price under the innovation-led lean programs. This is explained by the fact that the supplier seeks to discourage the manufacturer to undertake such a policy as the strategic innovation-led lean programs are more effective from an economic point of view. In fact, both firms will prefer the adoption of strategic innovation-led lean programs in most of the cases (i.e., model parameter regions). This policy, in fact, allows increasing the sales and decreasing the returns, while a process innovation lean strategy only works on the firms' profit margins. Further, the implementation of a strategic innovation-led lean programs entails a compensation effect between the price and the sales that the manufacturer is able to incline in favor of sustainability. In absence of strategic effect, innovation-led lean programs should only be pursued if process innovation effect exists. Otherwise, CLSCs should simply abandon the idea of becoming leaner.

We also examine the centralized (vertical integration) CLSC to investigate how the players would change their strategies in the absence of double marginalization effect. Intuitively, the centralized cases provide larger profits than the decentralized cases, thus suggesting the possibility to improve the profits by centralizing the CSLC and then finding an ad-hoc sharing rule. We find that the centralized CLSC prefers the adoption of a strategic innovation-led lean programs over a process innovation-led lean programs according to the same batch of features. The absence of the double marginalization does not change the decision maker's choices in terms of innovation-led lean programs and preferences in terms of strategic vs. process innovation effect.

\subsection{Limitations and Future Directions}

Our model is not free of limitations which could be improved in several ways. First, while we have assumed one-shot Stackelberg competition for the sake of analytic solution, the model could be extended to include multi-period strategic interactions. This could facilitate better understanding of performance of the lean programs in the long-run. For instance, one might then measure long-term environmental impact of those innovation-led lean programs. Second, it is natural to extend the model by allowing competition in both layers of the industries. This could be easily employed to the downstream in which multiple firms would compete for consumers and carry out lean activities. In fact, examining competition in innovation-led lean 
programs would be an interesting research direction as today's industries are heavily involved in adopting sophisticated innovation-led lean programs. Furthermore, allowing for competition in the downstream would be an alternative market mechanism to the case of vertical integration (i.e., the centralized solution). Third, in the current setting while the manufacturer carries out the lean innovation-led lean programs and bears the full cost, the supplier also benefits from these programs without sharing the cost of them. One could extend the model to allow splitting the costs of lean operations over the firms operating in upstream and downstream. Fourth, while we have focused on two types of innovation-led lean programs, one would include other forms of non-strategic (such as work-level) and strategic lean activities into an extended version of the model. These extensions could bring further insights into understanding of the impact of innovation-led lean programs in the supply chains.

\section{References}

[1] Aguado, S., Alvarez, R., \& Domingo, R. (2013). Model of efficient and sustainable improvements in a lean production system through processes of environmental innovation. Journal of Cleaner Production, $47,141-148$.

[2] Bocken, N. M., Short, S. W., Rana, P., \& Evans, S. (2014). A literature and practice review to develop sustainable business model archetypes. Journal of cleaner production, 65, 42-56.

[3] Bortolotti, T., Danese, P., Flynn, B. B., \& Romano, P. (2015). Leveraging fitness and lean bundles to build the cumulative performance sand cone model. International Journal of Production Economics, 162, $227-241$.

[4] De Giovanni, P.; Reddy, P. V. \& Zaccour, G. (2016), 'Incentive strategies for an optimal recovery program in a closed-loop supply chain', European Journal of Operational Research 249(2), 605-617.

[5] Chavez, R., Yu, W., Jacobs, M., Fynes, B., Wiengarten, F., \& Lecuna, A. (2015). Internal lean practices and performance: The role of technological turbulence. International Journal of Production Economics, $160,157-171$.

[6] Chiarini, A. (2014). Sustainable manufacturing-greening processes using specific Lean Production tools: an empirical observation from European motorcycle component manufacturers. Journal of Cleaner Production, 85, 226-233.

[7] D'Aspremont, C., \& Jacquemin, A. (1988). Cooperative and noncooperative R\&D in duopoly with spillovers. The American Economic Review, 78(5), 1133-1137. 
[8] De Giovanni, P. \& Ramani, V. (2017), 'Product cannibalization and the effect of a service strategy', Journal of the Operational Research Society, 1-17.

[9] De Giovanni, P. (2017), 'Closed-loop supply chain coordination through incentives with asymmetric information', Annals of Operations Research 253(1), 133-167.

[10] De Giovanni, P. \& Zaccour, G. (2014), 'A two-period game of a closed-loop supply chain', European Journal of Operational Research 232(1), 22-40.

[11] De Giovanni, P. (2017), 'Closed-loop supply chain coordination through incentives with asymmetric information', Annals of Operations Research 253(1), 133-167.

[12] Deif, A. M. (2011). A system model for green manufacturing. Journal of Cleaner Production, 19(14), 1553-1559.

[13] Dora, M., Kumar, M., Van Goubergen, D., Molnar, A., \& Gellynck, X. (2013). Operational performance and critical success factors of lean manufacturing in European food processing SMEs. Trends in Food Science \& Technology, 31(2), 156-164.

[14] Esenduran, G., Kemahlığlu-Ziya, E., \& Swaminathan, J. M. (2016). Take-Back Legislation: Consequences for Remanufacturing and Environment. Decision Sciences, 47(2), 219-256.

[15] Fercoq, A., Lamouri, S., Carbone, V., Lelièvre, A., \& Lemieux, A. A. (2013). Combining lean and green in manufacturing: a model of waste management. IFAC Proceedings Volumes, 46(9), 117-122.

[16] Fliedner, G., \& Majeske, K. (2010). Sustainability: the new lean frontier. Production and Inventory Management Journal, 46(1), 6-13.

[17] Fleishmann, M., Bloemhof-Ruwaard, J.M., Dekker, R., van der Laan, E., van Nunen, J.A.E.E. and Wassenhove, L.N.V. (1997), "Quantitative models for reverse logistics: a review", European Journal of Operational Research, Vol. 103, pp. 1-17.

[18] Genc, T. S., and De Giovanni, P. (2017). Trade-in and save: A two-period closed-loop supply chain game with price and technology dependent returns. International Journal of Production Economics, $183,514-527$.

[19] Genc, T.S. and G. Zaccour (2013). "Capacity Investments in a Stochastic Dynamic Game: Equilibrium Characterization", Operations Research Letters, 41(5), 482-485.

[20] Genc, T.S. (2017). "The Impact of Lead Time on Capital Investments", Journal of Economic Dynamics and Control, 82:142-164. 
[21] Gimenez C. and Sierra V.R.J. (2012). Sustainable Operations: Their Impact on the Triple Bottom Line. International Journal of Production Economics, 140: 149-159.

[22] Glover, W. J., Farris, J. A., Van Aken, E. M., \& Doolen, T. L. (2011). Critical success factors for the sustainability of Kaizen event human resource outcomes: An empirical study. International Journal of Production Economics, 132(2), 197-213.

[23] González-Benito, J., \& González-Benito, Ó. (2005). Environmental proactivity and business performance: an empirical analysis. Omega, 33(1), 1-15.

[24] Gotschol A, De Giovanni P., Vinzi VE. (2014). Is Environmental Management an Economically Sustainable Business? Journal of Environmental .Management; 144: 73-82.

[25] Guide Jr, V. D. R. \& Van Wassenhove, L. N. (2009), 'OR FORUM-The evolution of closed-loop supply chain research', Operations research 57(1), 10-18.

[26] Hong, X.; Govindan, K.; Xu, L. \& Du, P. (2017), 'Quantity and collection decisions in a closed-loop supply chain with technology licensing', European Journal of Operational Research 256(3), 820-829.

[27] Kaya, O. (2010), 'Incentive and production decisions for remanufacturing operations', European Journal of Operational Research 201(2), 442-453.

[28] Khanchanapong, T., Prajogo, D., Sohal, A. S., Cooper, B. K., Yeung, A. C., \& Cheng, T. C. E. (2014). The unique and complementary effects of manufacturing technologies and lean practices on manufacturing operational performance. International Journal of Production Economics, 153, 191-203.

[29] King, A. A., \& Lenox, M. J. (2001). Lean and green? An empirical examination of the relationship between lean production and environmental performance. Production and operations management, 10(3), $244-256$.

[30] Kobayashi, S. (2015). On a dynamic model of cooperative and noncooperative R and D in oligopoly with spillovers. Dynamic Games and Applications, 5(4), 599-619.

[31] Laroche, M., Bergeron, J., \& Barbaro-Forleo, G. (2001). Targeting consumers who are willing to pay more for environmentally friendly products. Journal of consumer marketing, 18(6), 503-520.

[32] Lluis, C.A., 2002. Design of a rapid response and high efficiency service by lean production principles: methodology and evaluation of variability of performance. International Journal of Production Economics $80(2), 169-183$. 
[33] Lucey, T. (2005). Management information systems. Cengage Learning EMEA.

[34] Martinez-Jurado PJ, Moyano-Fuentes J. (2013). Lean Management, Supply Chain Management and Sustainability: A Literature Review. J Clean. Prod.; 85: 134-150.

[35] Netland, T. H., Schloetzer, J. D., \& Ferdows, K. (2015). Implementing corporate lean programs: The effect of management control practices. Journal of Operations Management, 36, 90-102.

[36] Ostlin, J.; Sundin, E. \& Bjorkman, M. (2008), 'Importance of closed-loop supply chain relationships for product remanufacturing', International Journal of Production Economics 115(2), 336-348.

[37] Pampanelli, A. B., Found, P., \& Bernardes, A. M. (2014). A Lean \& Green Model for a production cell. Journal of cleaner production, 85, 19-30.

[38] Pil, F. K., \& Rothenberg, S. (2003). Environmental performance as a driver of superior quality. Production and Operations Management, 12(3), 404-415.

[39] Puvanasvaran, P., Swee, R. K., Suresh, V., \& Muhamad, M. (2012). Lean principles adoption in environmental management system (EMS)-ISO 14001. Journal of Industrial Engineering and Management, $5(2), 406$.

[40] Jasti N. and Kodali, R. (2015) Lean production: literature review and trends, International Journal of Production Research, 53:3, 867-885

[41] Ramani, V., \& De Giovanni, P. (2017). A two-period model of product cannibalization in an atypical Closed-loop Supply Chain with endogenous returns: The case of DellReconnect. European Journal of Operational Research, 262(3), 1009-1027.

[42] Rothenberg, S., Pil, F. K., and Maxwell, J. (2001). Lean, green, and the quest for superior environmental performance. Production and Operations Management, 10(3), 228-243.

[43] Savaskan, R. C.; Bhattacharya, S. \& Van Wassenhove, L. N. (2004), 'Closed-loop supply chain models with product remanufacturing', Management Science 50(2), 239-252.

[44] Savaskan, R. C. \& Van Wassenhove, L. N. (2006), 'Reverse channel design: the case of competing retailers', Management Science 52(1), 1-14.

[45] Sawhney, R., Teparakul, P., Bagchi, A., and Li, X. (2007). En-Lean: a framework to align lean and green manufacturing in the metal cutting supply chain. International Journal of Enterprise Network Management, 1(3), 238-260. 
[46] Shan, S., Wang, L., Xin, T., \& Bi, Z. (2013). Developing a rapid response production system for aircraft manufacturing. International Journal of Production Economics, 146(1), 37-47.

[47] Verrier, B., Rose, B., Caillaud, E., \& Remita, H. (2014). Combining organizational performance with sustainable development issues: the Lean and Green project benchmarking repository. Journal of Cleaner Production, 85, 83-93.

[48] von Stackelberg, H (2011). Market Structure and Equilibrium. 1st Edition Translation into English, Bazin, Urch

[49] Wong, W. P., \& Wong, K. Y. (2014). Synergizing an ecosphere of lean for sustainable operations. Journal of Cleaner Production, 85, 51-66.

[50] Yang, M. G. M., Hong, P., and Modi, S. B. (2011). Impact of lean manufacturing and environmental management on business performance: An empirical study of manufacturing firms. International Journal of Production Economics, 129(2), 251-261.

[51] Zhu, Q., \& Sarkis, J. (2004). Relationships between operational practices and performance among early adopters of green supply chain management practices in Chinese manufacturing enterprises. Journal of operations management, 22(3), 265-289.

\section{APPENDIX}

Proof of Proposition 1: The first order necessary condition with respect to retail price $p$ is $\frac{\partial \Pi^{M}}{\partial p}=\alpha-$ $2 \beta p+\sigma L+\beta\left(w+c_{M}-b_{M} L\right)=0$, which implies $p(L \mid w)=\frac{\alpha+\beta\left(w+c_{M}\right)+L\left(\sigma-\beta b_{M}\right)}{2 \beta}$. The profit maximizing level of lean activity obtained by $\frac{\partial \Pi^{M}}{\partial L_{M}}=0$ implies $L(p \mid w)=\frac{p\left(\sigma-b_{M} \beta\right)-w \sigma-c_{M} \sigma+\alpha b_{M}-\eta \Delta_{M}}{1-2 \sigma b_{M}}$. Let $K_{1} \equiv \sigma-\beta b_{M}$, $K_{2} \equiv-c_{M} \sigma+\alpha b_{M}-\eta \Delta_{M}, \quad K_{3} \equiv 1-2 \sigma b_{M}$ and $K_{4} \equiv \alpha+\beta c_{M}$. Then we can rewrite the strategies in a compact way so that $L(p \mid w)=\left(K_{1} p-\sigma w+K_{2}\right) / K_{3}$ and $p(L \mid w)=\left(K_{1} L_{M}+\beta w+K_{4}\right) / 2 \beta$. Solving them simultaneously yields $p(w)=\frac{K_{1} K_{2}+K_{3} K_{4}+\left(\beta K_{3}-\sigma K_{1}\right) w}{2 \beta K_{3}-K_{1}^{2}}$ and $L(w)=\frac{K_{1} K_{4}+2 \beta K_{2}+\beta\left(K_{1}-2 \sigma\right) w}{2 \beta K_{3}-K_{1}^{2}}$. These $p(w)$ and $L(w)$ are the best response functions of $M$ for a given level of wholesale price $w$ chosen by $S$. Observe that the retail price of the final product and the level of lean depend on demand and return function parameters as well as upstream supplier's decision. Furthermore, $\frac{\partial L}{\partial w}<0$, that is lean activity decreases in wholesale price and $\frac{\partial p}{\partial w}>0$, that is retail price increases in wholesale price. All other things equal, increase in cost of production via wholesale price causes $M$ to reduce other costly activities such as lean. Therefore, we obtain this negative relation between the wholesale price and leanness. In the upstream, the supplier's objective function is $\Pi^{S}=(\alpha-\beta p(w)+\sigma L(w))\left(w-c_{S}+b_{S}\right)$. The maximization with respect to its wholesale price $w$ 
yields $w=\frac{\left(c_{S}-b_{S}\right)}{2}-\frac{K_{5}}{K_{6}}$, where $K_{5} \equiv \alpha-\beta \frac{K_{1} K_{2}+K_{3} K_{4}}{2 \beta K_{3}-K_{1}^{2}}+\sigma \frac{\left(K_{1} K_{4}+2 \beta K_{2}\right)}{2 \beta K_{3}-K_{1}^{2}}$, and $K_{6} \equiv \frac{\sigma \beta\left(K_{1}-2 \sigma\right)}{2 \beta K_{3}-K_{1}^{2}}-\beta \frac{\beta K_{3}-\sigma K_{1}}{2 \beta K_{3}-K_{1}^{2}}$. Observe that wholesale price increases in cost of making the intermediate good but it reduces whenever we have lean process innovation $\left(b_{S}>0\right)$.

Proof of Corollary 1: In this benchmark CLSC model, the equilibrium outcomes can be obtained when the coefficients $\sigma, \eta, b_{S}, b_{M}$ become zero in Proposition 1. Without any lean program the profit function of the manufacturer is $\Pi_{1}^{M}\left(p_{1} \mid w_{1}\right)=\left(\alpha-\beta p_{1}\right)\left(p_{1}-w_{1}-c_{M}\right)+\theta \Delta_{M}$ and the profit function of the supplier is $\Pi_{1}^{S}\left(w_{1} \mid\right.$ $\left.p_{1}\right)=\left(\alpha-\beta p_{1}\right)\left(w_{1}-c_{S}\right)$. We solve the problem backwards starting with $M$. The maximization with respect to its retail price $p_{1}$ yields $p_{1}\left(w_{1}\right)=\frac{\alpha+\beta\left(w_{1}+c_{M}\right)}{2 \beta}$. Then $S$ takes $M$ 's pricing strategy into account before it chooses its wholesale price. The supplier's objective function becomes $\Pi_{1}^{S}\left(w_{1}\right)=\left(\alpha-\beta \frac{\alpha+\beta\left(w_{1}+c_{M}\right)}{2 \beta}\right)\left(w_{1}-c_{S}\right)$. The maximization with respect to its wholesale price $w_{1}$ yields $w_{1}=\frac{\alpha+\beta\left(c_{S}-c_{M}\right)}{2 \beta}$. Inserting this into wholesale price function, we then obtain the equilibrium strategies in the corollary.

Proof of Proposition 2: Given $w_{2}, M$ maximizes its objective function. The maximization with respect to its retail price $p_{2}$ yields $p_{2}\left(w_{2}, L_{2}\right)=\frac{\alpha+\beta\left(w_{2}+c_{M}\right)+\sigma L_{2}}{2 \beta}$, while the lean activity level is $L_{2}\left(w_{2}, p_{2}\right)=$ $\sigma\left(p_{2}-w_{2}-c_{M}\right)-\eta \Delta_{M}$

Solving these strategies together we obtain the pair $p_{2}\left(w_{2}\right)=\frac{\alpha+\beta\left(w_{2}+c_{M}\right)-\sigma\left(\sigma\left(w_{2}+c_{M}\right)+\eta \Delta_{M}\right)}{2 \beta-\sigma^{2}}$ and $L_{2}\left(w_{2}\right)=$ $\frac{\sigma\left(\alpha-\beta\left(w_{2}+c_{M}\right)\right)-2 \beta \eta \Delta_{M}}{2 \beta-\sigma^{2}}$.We insert these strategies into $M$ 's objective function and maximize it with respect to $w_{2}$ to obtain $w_{2}=\frac{\alpha+\beta\left(c_{S}-c_{M}\right)-\sigma \eta \Delta_{M}}{2 \beta}$. Inserting this into wholesale price function and lean activity function, we then obtain the equilibrium strategies in the proposition.

Proof of Proposition 3: When there is no any lean activity the prices are defined in Corollary 1. With strategic lean the prices are as in Proposition 2. The wholesale prices of the intermediate product with and without lean are $w_{2}=\frac{\alpha+\beta\left(c_{S}-c_{M}\right)-\sigma \eta \Delta_{M}}{2 \beta}$ and $w_{1}=\frac{\alpha+\beta\left(c_{S}-c_{M}\right)}{2 \beta}$, respectively. Clearly, $w_{1}>w_{2}$ because the third term in $w_{2}$ is negative. Observe that when lean activity is nil, that is, either $\sigma$ or $\eta$ is zero, $w_{2}$ becomes identical to $w_{1}$. From the proof of Proposition 2 we know that $p_{2}\left(w_{2}\right)=\frac{\alpha+\beta\left(w_{2}+c_{M}\right)-\sigma\left(\sigma\left(w_{2}+c_{M}\right)+\eta \Delta_{M}\right)}{2 \beta-\sigma^{2}}$. The rate of change of retail price with respect to wholesale price is $\frac{\partial p_{2}}{\partial w_{2}}=\left(\beta-\sigma^{2}\right) /\left(2 \beta-\sigma^{2}\right)$ which must be positive as $w_{2}$ is an input cost for $M$ and increase in its cost will be reflected to its final price because $M$ is a profit maximizing monopoly. This implies that the numerator $\beta-\sigma^{2}>0$ must hold. This also guarantees that the denominator is also positive. Furthermore, observe that $\underset{\sigma \rightarrow 0}{\lim } p_{2}=p_{1}$. In addition, $\frac{\partial p_{2}}{\partial \sigma}=\frac{2 \alpha \beta \sigma+\eta \Delta_{M}\left(3 \beta \sigma^{2}-\sigma^{4}-6 \beta^{2}\right)+2 \beta\left(c_{S}+c_{M}\right)\left(\sigma \beta+\sigma^{2}-2 \beta-\sigma^{3}\right)}{2 \beta\left(2 \beta-\sigma^{2}\right)^{2}}>0$ because the last two terms are negative but very small and the first term is positive and very large. This implies that the minimum of $p_{2}$ is attained when $\sigma$ is the minimum. Therefore, $p_{2}>p_{1}$ for a positive $\sigma$.

Proof of Proposition 4: We solve the problem backwards starting with $M$. The maximization with respect to its retail price $p_{3}$ yields to $p_{3}\left(w_{3}, L_{3}\right)=\frac{\alpha+\beta\left(w_{3}+c_{M}\right)-\beta b_{M} L_{3}}{2 \beta}$ and process innovation is $L_{3}\left(p_{3}\right)=$ $\left(\alpha-\beta p_{3}\right) b_{M}$. Solving $L_{3}\left(p_{3}\right)$ and $p_{3}\left(w_{3}, L_{3}\right)$ together we obtain $M$ 's strategies in terms of $S$ 's strategy 
$p_{3}\left(w_{3}\right)=\frac{\alpha\left(1-\beta b_{M}^{2}\right)+\beta\left(w_{3}+c_{M}\right)}{\beta\left(2-\beta b_{M}^{2}\right)}$ and $L_{3}\left(w_{3}\right)=b_{M} \frac{\alpha-\beta\left(w_{3}+c_{M}\right)}{2-\beta b_{M}^{2}}$. Then $S$ takes $M$ 's pricing strategy into account before it chooses its wholesale price. The supplier's objective function becomes $\Pi_{3}^{S}\left(w_{3}\right)=(\alpha-$ $\left.\beta \frac{\alpha\left(1-\beta b_{M}^{2}\right)+\beta\left(w_{3}+c_{M}\right)}{\beta\left(2-\beta b_{M}^{2}\right)}\right)\left(w_{3}-c_{S}+b_{S}\right)$. The first order necessary condition with respect to its wholesale price $w_{3}$ leads to $w_{3}=\frac{\alpha+\beta\left(c_{S}-c_{M}-b_{S}\right)}{2 \beta}$. Inserting this into wholesale price function and process innovation function, we then obtain the equilibrium strategies in the proposition.

Proof of Proposition 5: Because $b_{S}>0$ the wholesale prices compare $w_{3}=\frac{\alpha+\beta\left(c_{S}-c_{M}-b_{S}\right)}{2 \beta}<\frac{\alpha+\beta\left(c_{S}-c_{M}\right)}{2 \beta}=$ $w_{1}$. The difference between the retail prices is $p_{3}-p_{1}=\frac{-b_{M}^{2}\left(\alpha-\beta\left(c_{S}+c_{M}\right)\right)-2 b_{S}}{4 \beta\left(2-\beta b_{M}^{2}\right)}<0$. Because $b_{S}>0$ by assumption and $\alpha-\beta\left(c_{S}+c_{M}\right)>0$ by expression (18) in which wholesale price $\left(w_{1}\right)$ is greater than marginal cost of production $c_{S}$.

Proof of Proposition 6: The maximization with respect to retail price gives $p(L)=\frac{\alpha+\left(\sigma-\beta b_{M}\right) L+\beta c}{2 \beta}$ where $c=c_{M}+c_{S}-b_{S}$. The profit maximizing level of lean activity gives $L(p)=\frac{(p-c) \sigma-\eta \Delta_{M}+(\alpha-p \beta) b_{M}}{1-2 \sigma b_{M}}$. Solving these equations simultaneously and substituting in the objective function we obtain the optimal strategies and profits for the vertical integration case.

Proof of Proposition 7: The maximization with respect to the retail price gives $p(L)=\frac{\alpha+\sigma L+\beta\left(c_{M}+c_{S}\right)}{2 \beta}$ and the lean program strategy is $L(p)=\left(p-\left(c_{M}+c_{S}\right)\right) \sigma-\eta \Delta_{M}$. Solving these equations simultaneously and substituting in the objective function we obtain the optimal strategies and profits for the vertical integration case.

Proof of Proposition 9: The maximization with respect to retail price gives $p(L)=\frac{\alpha-\beta b_{M} L+\beta c}{2 \beta}$ where $c=c_{M}+c_{S}-b_{S}$. Interestingly, one can see that $\frac{\partial p(L)}{\partial L}=-\frac{b_{M}}{2}<0$ always holds. Thus, when lean activities do not supply any effect on the demand, the price reflects the benefits obtained in operations and reduces accordingly. Thus, the larger the operational gains due to lean activities, the lower the price. The lean activity gives $L(p)=(\alpha-p \beta) b_{M}$. Solving these equations simultaneously and substituting in the objective function we obtain the optimal strategies and profits for the vertical integration case. 